
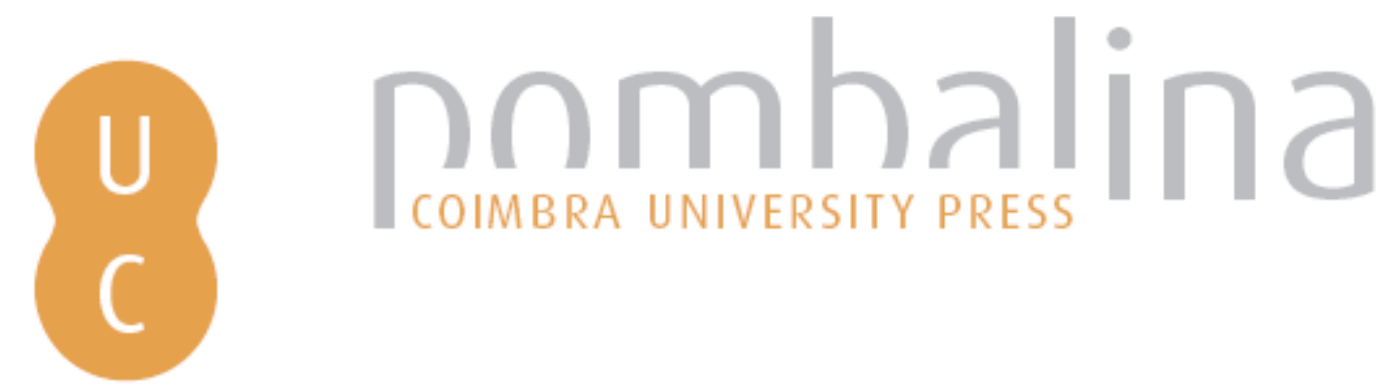

\title{
Arquivos coloniais e representações da alteridade nos documentários do Estado Novo: o caso das imagens em movimento da Cinemateca Digital
}

Autor(es): Rosa, Francesca de

Publicado por: Imprensa da Universidade de Coimbra

URL

persistente: URI:http://hdl.handle.net/10316.2/43882

DOI: $\quad$ DOI:https://doi.org/10.14195/978-989-26-1395-6_11

Accessed : $\quad$ 26-Apr-2023 08:05:50

A navegação consulta e descarregamento dos títulos inseridos nas Bibliotecas Digitais UC Digitalis, UC Pombalina e UC Impactum, pressupõem a aceitação plena e sem reservas dos Termos e Condições de Uso destas Bibliotecas Digitais, disponíveis em https://digitalis.uc.pt/pt-pt/termos.

Conforme exposto nos referidos Termos e Condições de Uso, o descarregamento de títulos de acesso restrito requer uma licença válida de autorização devendo o utilizador aceder ao(s) documento(s) a partir de um endereço de IP da instituição detentora da supramencionada licença.

Ao utilizador é apenas permitido o descarregamento para uso pessoal, pelo que o emprego do(s) título(s) descarregado(s) para outro fim, designadamente comercial, carece de autorização do respetivo autor ou editor da obra.

Na medida em que todas as obras da UC Digitalis se encontram protegidas pelo Código do Direito de Autor e Direitos Conexos e demais legislação aplicável, toda a cópia, parcial ou total, deste documento, nos casos em que é legalmente admitida, deverá conter ou fazer-se acompanhar por este aviso.

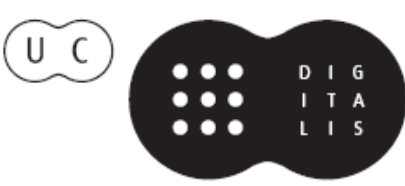



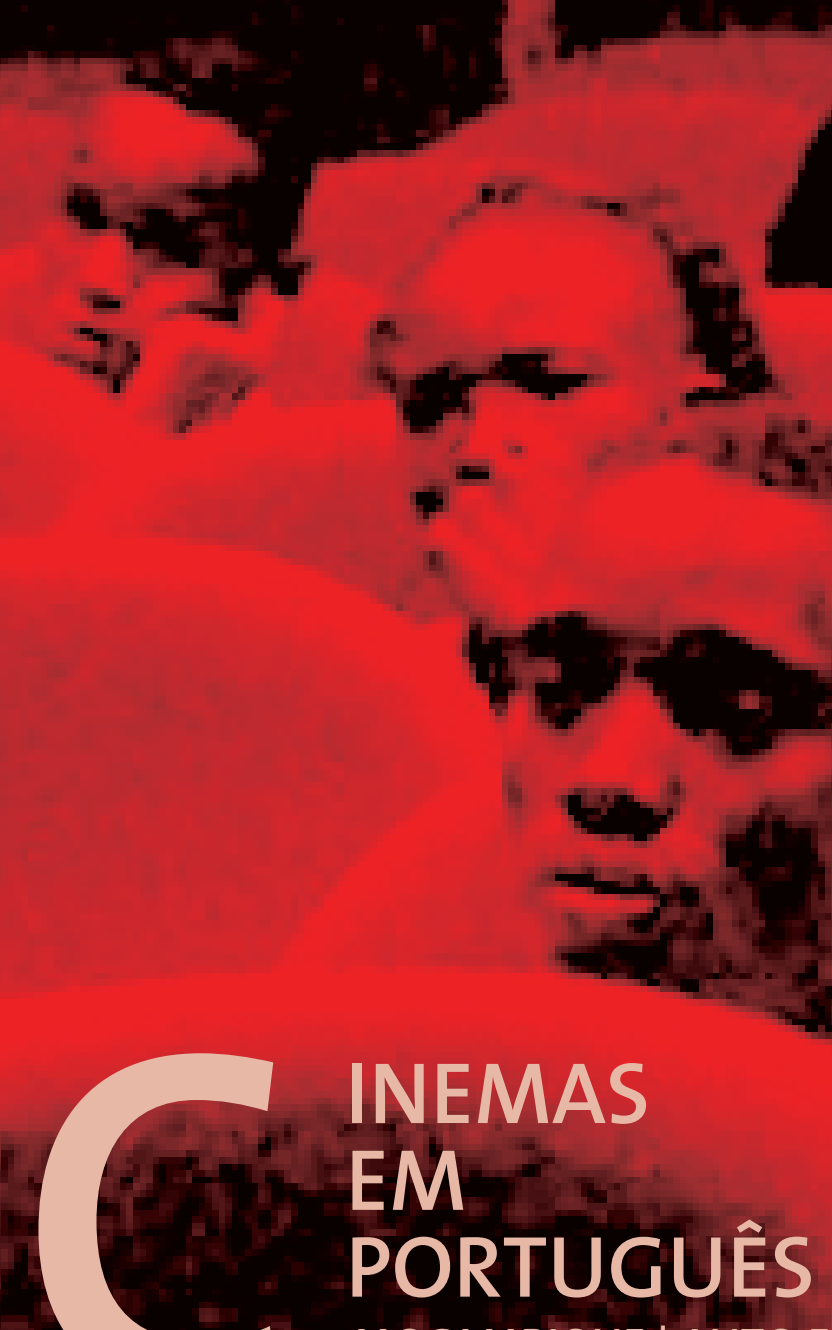

INEMAS

EM

PORTUGUÊS

MOÇAMBIQUE | AUTO E HETEROPERCEÇÕES

JORGE SEABRA

COORDENAÇÃO 


\section{ARQUIVOS COLONIAIS E REPRESENTAÇÕ ES DA ALTERIDADE NOS DOCUMENTÁRIOS DO ESTADO NOVO. O CASO DAS IMAGENS EM MOVIMENTO DA CINEM ATE CA D I G ITAL}

Francesca De Rosa (UNIOR, Itália)

The transformation of archival activity is the point of departure and the condition of a new history (Mbembe, 2002, p. 20)

Queria começar a intervenção com uma pergunta colocada na introdução do livro Visual Culture Reader, Race and identity, colonial and postcolonial culture por Nicholas Mirzoeff a respeito do papel central da experiência do colonialismo e da escravidão (Mirzoeff, 1998, pp. 281-290), em que a supremacia racial europeia através da visualização das diferenças raciais tem representado a chave das culturas visuais ocidentais ao longo da modernidade: será que existem modos não-racializados de olhar às pessoas? (Mirzoeff, 1998, pp. 281-290).

Na minha intervenção tento analisar, a partir da filmografia presente na Cinemateca Digital Portuguesa ${ }^{1}$, colecção do Arquivo Nacional das Imagens em Movimento (ANIM), o discurso documental do Império colonial português e o conceito de arquivo.

${ }^{1}$ Os videos estão disponibilizados no Site da Cinemateca Portuguesa no seguinte link: http://www.cinemateca.pt/Cinemateca-Digital/Video

DOI: https://doi.org/10.14195/978-989-26-1395-6_11 
Por um lado questiono-me sobre o dispositivo do arquivo, da abertura e re-elaboração dos seus conteúdos para a compreensão e superação ou reconhecimento daquele passado colonial que ainda hoje contém fortes relações entre memória, história e o que estas imagens nos dizem; por outro lado, tento oferecer algumas informações sobre os documentários pertencentes à colecção da Cinemateca Portuguesa (CP).

Para começar acho fundamental, no debate a volta dos arquivos, contextualizar o critério de acessibilidade, elemento que muitas vezes depende do carácter formal ou informal do arquivo, da instituição a que pertence e do arquivo ser digital ou um espaço meramente físico, sublinhando a dificuldade que se manifesta em ter acesso a arquivos cuja relação com o passado denota o carácter problemático entre história e memória.

Em relação aos arquivos institucionais e oficiais, a prática da $e x-$ clusão é uma das características destas instituições, onde o excluído representa a memória do corpo institucional, como refere Jacques Derrida, uma instituição tem que questionar a memória do que ela exclui e que tenta de forma selectiva entregar ao esquecimento. A superfície do seu arquivo é caracterizada pelo que ela mantém fora, que expulsa ou que já não tolera. E assim, o excluído, cujos traços são esculpidos no seio do arquivo, na superfície institucional, acaba ele mesmo por se tornar no sujeito que contém a memória do corpo institucional (Derrida,1990).

No ensaio Burning Archives, La memoria del corpo tra archivi etnografici, colonialismo e arte contemporanea, Giulia Grechi faz uma narração crítica da profunda ambiguidade à base da operação de arquivamento apresentando a dualidade entre memória e desejo (Grechi, 2014). A autora explica como as práticas de recolha, classificação e categorização que tem produzido a reprodução de arquivos entre o Século XIX e XX, representam o campo Ocidental na medida em que, falando destes dispositivos, aos conceitos de acumulação 
e preservação são associados os de temporalidade e ordem, estes últimos bem radicados nesta cultura e perspectiva (Grechi, 2014).

$\mathrm{Na}$ época dos database digitais e dos network informáticos, o arquivo é aquele modelo que nos oferece uma multiplicidade reticular, heterogénea e disseminada, com duração variável, não é só contar através do arquivo, mas re-contar cada vez de maneira diferente e descontínua, relações de poder, de saber e de subjectividades. Como sugere Marco Scotini numa entrevista de 25 de Junho de $2014^{2}$ o arquivo, por estatuto, tem carácter empírico, prático, e a sua existência é sempre temporária, trata-se, portanto de des-arquivar e re-arquivar continuamente o material.

$\mathrm{O}$ arquivista, e eu acrescentaria, quem trabalha e usa o material do arquivo, lida com uma construção pragmática, artificial e portanto contingente: algo que nunca foi concluido e num continuo processo de execução.

Scotini acrescenta que o carácter de contemporaneidade do arquivo depende da pluralidade que existe dentro dele, nestas palavras acho possível encontrar parte dalguns aspectos emblemáticos a respeito do arquivo, isto é, o uso e (re)uso do material guardado através de conceitos como pluralidade, possibilidade de des-arquivar e re-arquivar, possibilidade de dar leituras ao material que o arquivo contém, possibilidade de re-contar a partir da fragmentariedade intrínseca deste lugar com que lidamos e que nos fala por dentro e por fora das relações de poder.

\section{Arquivar as imagens em movimento - o caso português}

Como bem apresenta o estudioso Tiago Baptista em relação ao contexto cinematográfico e de arquivação português podemos consi-

2 Deianira, Amico, Entrevista a Marco Scotini: "l'archivio come dispositivo tra estetica e pedagogia", http://news.mytemplart.com/it/intervista-marco-scotinilarchivio-come-dispositivo-tra-estetica-e-pedagogia/ (2014) 
derar Manuel Felix Ribeiro, "o conservador" do cinema em Portugal, o homem-arquivo, personagem que já no período do Estado Novo, com a Política do Espírito de António Ferro, pensava na arte e na divulgação cultural como factores importantes achando fundamental a recuperação dos documentários portugueses para a criação de uma colecção nacional cinematográfica (Baptista, 2012, pp. 37-42).

Recolhendo filmes, livros e fotografias, Félix Ribeiro julgava necessária a criação de novas técnicas para a preservação destes materiais e a criação de infraestruturas apropriadas à conservação. Neste sentido, será teórico do conceito de cinema nacional, da sua preservação, diretor da Filmoteca do Secretariado de Propaganda Nacional (SPN) e da Cinemateca Portuguesa entre 1948 e 1982.

Vale a pena salientar que ambas as colecções, a da Cinemateca e a da Filmoteca do SPN, para além de serem chefiadas pela mesma pessoa ao longo de 40 anos, partilharam também o mesmo espaço físico de conservação até 1978.

O desejo de Félix Ribeiro de criar uma Cinemateca Nacional tem data de 1931 quando, com o realizador António Lopes Ribeiro, conseguiu incluir na relação sobre cinema sonoro, que antecipava a criação da Produtora Cinematográfica Tobis Portuguesa, uma referência sobre a necessidade do Estado criar um arquivo fílmico (Baptista, 2012). A ideia nascia, como no resto da Europa, da noção de que a passagem ao cinema sonoro teria sido uma ameaça para a sobrevivência do cinema mudo.

Nos anos trinta, realizadores como António Lopes Ribeiro, autor de vários documentários e filmes sobre as ex-colónias portuguesas em África, como Feitiço do Império e membro da Missão Cinematográfica às Colónias de África em 1938, com Fernando Fragoso, lançam uma campanha de preservação destes documentários. Como afirma Tiago Baptista, diferentemente do que acontecia noutros países da Europa, o que interessava mais era a ideia de conservação deste material numa espécie de "Torre de Tombo", mais do que o estatuto de cinema como 
obra de arte, interessava, portanto, um cinema que tivesse "interesse histórico, que [pudesse] contribuir para o (...) estudo de uma época." 3

Fundada em 1948 con Decreto-Lei $n^{\circ} 2027$ e integrada nos serviços do SNI (Sercretariado Nacional de Informação), a Cinemateca Portuguesa tem hoje a sua colecção, no centro ANIM em Bucelas.

O espaço digital da Cinemateca nasce dentro do projecto European Film Gateway composto por 16 cinematecas e arquivos fílmicos europeus. Conforme os dados fornecidos pelo site, os critérios de selecção do material cinematográfico apresentam a digitalização de documentários entre 1886 e 1931, a colecção digital que antes de Setembro de 2013 contava com 170 filmes, ve-se hoje com a presença de outros filmes disponibilizados nos últimos meses de 2014.

A partir de Setembro de 2015, dentro deste espaço, a colecção que antes contava com a digitalização de nove produções de temática colonial continua a crescer com vários documentários sobre o antigo Império Colonial Português em África.

O que é que nos dizem estas imagens?

Primeiro que a maioria destes filmes foram concebidos para serem exibidos nas diferentes exposições coloniais, poucos foram exibidos nas sessões de cinema, a não ser em eventos coloniais com a presença de altos cargos do Estado, e deduzimos também que dentro do espaço digital do arquivo da Cinemateca Portuguesa encontramos hoje os documentários das três missões naquela altura encomendadas para estes eventos.

A produção portuguesa de temática colonial dos anos vinte será projectada na Exposição Ibero-Americana de Sevilha (1929), na Exposição Internacional e Colonial de Antuérpia (1930) e na Exposição Colonial de Paris (1931) através da primeira iniciativa estatal concertada e sis-

${ }^{3}$ A ler os artigos de Fernando Fragoso "É preciso quanto antes uma cinemateca nacional", Cine Jornal, 20 Jun. 1938 n..$^{\circ}$ 140, p.10 e de António Lopes Ribeiro "Porque não se constitui uma "Torre do Tombo" com filmes de interesse histórico", Animatógrafo, 9 Jun. 1941, n. ${ }^{\circ} 31$, p. 6. 
temática para produzir filmes sobre todas as colónias africanas. E a tal propósito, a Agência Geral das Colónias e o Comissário da Exposição de Sevilha, Armando Cortesão encomendaram, por indicação do então Ministro das Colónias, Armindo Monteiro, filmes sobre os territórios africanos a três equipas de cineastas.

1. $\mathbb{1}^{\mathrm{a}}$ Companhia de Infantaria Indígena de Angola em Lisbôa Portugal, 1933, Duração: 00:11:59

2. $1^{\text {a Exposição Colonial Portuguesa }}$ - Porto 1934 Aníbal Contreiras (1898-1993)

- Realizador Portugal, 1934

Duração: 00:07:16

3. A Cidade de Lourenco Marques Fernandes Tomaz - Realização Portugal, 1929

Duração: 00:12:02

4. A Cultura do Cacau Ernesto de Albuquerque (1883-1940) - Realizador Ernesto de Albuquerque (1883-1940) Director de fotografia Portugal, 1909 Duração: 00:01:32

5. A Exposição do Mundo Português F. Carneiro Mendes (1893-1976) Realizador

F. Carneiro Mendes (1893-1976) Director de fotografia

Portugal, 1940 Duração: 00:10:46

6. Accão Colonizadora dos Portugueses António Antunes da Mata - Realização José César de Sá (1905-1976) Director de fotografia Portugal, 1932 Duração: 00:21:41

7. Agricultura de Moçambique Portugal, 1949 Duração: 00:11:10

8. Angola - Exposição Provincial, Agrícola, Pecuária e Industrial 1923 Portugal, 1923 Duração: 00:11:49
9. Angola Aspectos Históricos Manoel Figueira - Autor Peixinho - Director de fotografia Portugal, 1938 Duração: 00:12:16

10. Aspectos do Rio Quanza: Quedas do Lucala António Antunes da Mata - Realização José César de Sá (1905-1976) Director de fotografia Portugal, 1930 Duração: 00:14:31

11. Chegada da Viagem Aérea LisboaLourenço Marques-Lisboa Artur Costa de Macedo (1894-1966) Realização Artur Costa de Macedo (1894-1966) - Director de fotografia Portugal, 1936 Duração: 00:05:05

12. Costumes Primitivos dos Indígenas Em Moçambique Fernandes Tomaz - Realização Portugal, 1929 Duração: 00:14:54

13. De Lisboa a Luanda António Antunes da Mata - Realização José César de Sá (1905-1976) Realização José César de Sá (1905-1976) Director de Fotografia Portugal, 1932Duração: 00:15:54

14. De Lisboa a São Tomé António Antunes da Mata - Realização José César de Sá (1905-1976) Director de fotografia Portugal, 1933 Duração: 00:07:24 
15. Dragões de Moçambique

Fernandes Tomaz - Realizador

Fernandes Tomaz - Director de fotografia

Aníbal Contreiras (1898-1993) -

Produtor- Distriduidor

Portugal, 1934 Duração: 00:22:54

16. Fazenda Açucareira "Tentativa" António Antunes da Mata - Realização José César de Sá (1905-1976) - Director de fotografia

Portugal, 1932 Duração: 00:11:38

17. Festejos Em Lourenço Marques Pela

Passagem dos Territórios

do Niassa Para a Posse do Estado

Fernandes Tomaz - Realizador-

Portugal, 1929-Duração: 00:05:54

18. Guiné - Aldeia Indígena em Lisboa

Portugal, 1932 Duração: 00:12:25

19. Guiné : Aspectos Industriais e

Agricultura

Augusto Seara - Realizador Portugal, 1929 Duração: 00:12:34

20. Ilha de Moçambique - Imagens duma

Velha Capital Histórica

Carlos Marques - Realizador Alfredo

Cristino Gomes - Director de fotografia

Portugal,

1951 Duração: 00:06:44

21. Indústria Portuguesa de Algodão -

Fabrica da Areosa

Glória Film - Companhia Produtora

Portugal, 1934 Género: Documentário

Duração: 00:21:07

22. Missão Académica a Angola - Alguns

Aspectos Cinematográficos da Viagem

Maximino Correia (1893-1969) -

Realizador Portugal, 1929

Duração: 00:33:33
23. No País das Laurentinas (Colonos)

Ismael da Costa - Realizador Fernandes

Tomaz - Director de fotografia

Ismael da Costa - Intertítulos Portugal, 1934

Duração: 00:36:36

24. 0 Deserto de Angola

António Antunes da Mata - Realização José César de Sá (1905-1976) - Director de fotografia

António Antunes da Mata - Intertítulos

Portugal, 1932

Duração: 00:08:10

25. Planalto de Huila

António Antunes da Mata - Realizador

José César de Sá (1905-1976) -

Realizador

26. Primeira Exposição Colonial Portuguesa

Aníbal Contreiras (1898-1993) -

Realização

Aníbal Contreiras (1898-1993) -

Director de fotografia

José César de Sá (1905-1976) - Director de Fotografia

F. A. Quintela - Som Portugal, 1935

Duração: 00:35:57

F. A. Quintela - Produtor José César de

Sá (1905-1976) - Director de fotografia

Portugal, 1931 Duração: 00:18:55

27. Quedas do Dala - Angola

José César de Sá (1905-1976) -

Realização

António Antunes da Mata - Realização

Portugal, 1930 Duração: 00:06:28

28. São Tomé Agrícola e Industrial Augusto Seara - Realizador Portugal, 1929 Duração: 00:11:47

Documentários de temática colonial presentes na secção digital da

Cinemateca Portuguesa 
Conforme as informações disponibilizadas por Maria do Carmo Piçarra na obra Azuis Ultramarinos, e as informações contidas nos textos da Cinemateca Portuguesa de Joana Pimentel, a primeira equipa a partir foi a dos Serviços Cartográficos do Exército, a que se juntou o operador Augusto Seara, e que produziram filmes sobre S. Tomé e Príncipe e Guiné. Do material filmado em S. Tomé existem $S$. Tomé agrícola e industrial (1929, 10') e da Guiné, Guiné, aspectos industriais e agrícolas $\left(1929,11^{\prime}\right)$, ambos presentes na cinemateca digital.

Outra equipa, a da Missão Cinegráfica a Angola, composta por César de Sá e António Antunes da Mata, partiu quase em simultáneo com a chefiada por Seara. No regresso, Antunes da Mata foi encarregue da montagem e titulagem dos filmes destinados às exposições, e posteriormente à distribuição interna no circuito de exibição.

Dirigida por João Fernandes Tomás, a Brigada Cine-Portuguesa tinha Moçambique como destino e, desta produção sabemos também que parte das imagens captadas foram montadas num filme, A colónia de Moçambique, que ganhou um grande prémio na Exposição de Paris.

Em 1982, entre os filmes depositados na Cinemateca pela entretanto extinta AGU, apareciam também outros títulos de 1929: A cidade de Lourenço Marques (212 metros, incompleto), Festejos em Lourenço Marques pela passagem dos territórios do Niassa para a posse do Estado (1929, 4') e Costumes primitivos dos indigenas de Moçambique (1929, 12'). A Tomás foi atribuída também a primeira longa-metragem filmada em Moçambique, "Através de Portugal Maior de 1928", desaparecida (Piçarra, 2012; Pimentel, 2007, pp. 367-368).

No percurso que o arquivo digital propõe, com base nas informações que há pouco referi, com o acréscimo dos outros documentários a partir de setembro de 2014, os filmes destas missões disponibilizados para o visionamento são: 


\begin{tabular}{|l|}
\hline Costumes Primitivos dos Indígenas em Moçambique (1929) \\
\hline $\begin{array}{l}\text { Festejos em Lourenço Marques pela Passagem dos Territórios do Niassa para } \\
\text { a Posse do Estado (1929) }\end{array}$ \\
\hline Guiné- Aspectos Industriais e Agrícultura (1929) \\
\hline São Tomé Agrícola e Industrial (1929) \\
\hline Estradas e Paisagens de Angola (1929) \\
\hline Quedas do Dala (1930) \\
\hline Aspectos do rio Quanza. Quedas do Lucala (1930) \\
\hline Planalto de Huila (1931) \\
\hline Accão colonizadora dos portugueses (1932) \\
\hline De Lisboa a Luanda (1932) \\
\hline 0 deserto de Angola (1932) \\
\hline Pesca da baleia em Angola (1932) \\
\hline Fazenda Açucareira "Tentativa" (1932) \\
\hline De Lisboa a Sao Tomé (1933) \\
\hline
\end{tabular}

Vale a pena referir que desta altura, no ANIM, mas ainda não disponibilizado na cinemateca digital, tive a oportunidade de visionar o filme Uma visita às propriedades da Sociedade Agricola Valle Flor, Limitada na Ilha de S.Thomé, de Fernandes Thomas, da Brigada Cinematográfica Portuguesa, de 1929, com duração de 70 minutos, cujas informações relativas aos aspectos e às condições de trabalho

\footnotetext{
${ }^{4}$ Para além dos filmes acima citados, a Cinemateca Digital disponibiliza sobre a tematica colonial os seguintes documentrios: A cidade de Lourenço Marques, Fernandes Tomaz, 1929; Costumes Primitivos dos Indigenas em Moçambique, Fernandes Tomaz, 1929; Festejos em Lourenço Marques pela passagem dos territórios do Niassa para a posse do Estado, Fernandes Tomaz, 1929; Guiné: aspectos industriais e agricultura, Augusto Seara, 1929; São Tomé, Agrícola e Industrial, Augusto Seara, 1929; Missão Académica a Angola-alguns aspectos cinematográficos da viagem, Maximino Correia, 1929; Quedas do Dala, A. A. da Mata, César de Sá, 1930; Aspectos do Rio Quanza: Quedas do Lucala, A. A. da Mata, César de Sá, 1930; O deserto de Angola, A. A. da Mata, J.C. de Sá, 1932; De Lisboa a Luanda, 1, A. A. da Mata J.C. de Sá, 1932; Planalto de Huila, A. A. da Mata, J.C.de Sá, 1931; Fazenda Açucareira Tentativa, A. A. da Mata 1932; Acção colonizadora dos portugueses A. A. da Mata, 1932; África em Lisboa- Os indígenas da Guiné na Grande Exposição Industrial, 1932; Raul Reis Salazar Dinis, $1^{\circ}$ Companhia de Infantaria Indígena de Angola em Lisboa, AGC, 1933; Indústria Portuguesa de Algodão - Fábrica da Areosa, Glória Film, 1934; No pais das Luarentinas e Dragões de Moçambique, 1934.
} 
e de pagamentos dos "nativos" representam imagens raras e quase uma excepção.

Para além do testemunho que essas imagens nos oferecem em relação ao trabalho forçado, à exploração, à vida nas ex-colónias, o que parece interessante é a interpretação e a construção que através das imagens em movimento Portugal constrói de si próprio. Tratam-se de imagens funcionais do Império, que justificam a acção colonizadora, e que nos deixam refletir sobre a ideia de que seja ou não cinema.

A esta pergunta, Maria do Carmo Piçarra, nas obras Angola o nascimento de uma nação e Azuis Ultramarinos responde que são filmes em que não há cinema, nao há olhar. Ficam-se, em geral, pelo mero registo da paisagem natural ou humana feito com imagens em movimento mas sem acrescentar muito mais do que faria uma sucessão de imagens fixas fotografadas mecanicamente. Os intertítulos são usados para explicar o que é visto e fazem ligação entre cenas (Piçarra, 2012, p. 63).

$\mathrm{Na}$ realidade, na minha opinião, em relação a questão do olhar, o que poderiamos acrescentar é que por mais que se trate de filmes "sem cinema" é um cinema com um olhar cujos objectivos parecem muito claros, isto é, a proclamação da identidade colonial e da grandeza dos portugueses com base numa estética que poderiamos definir de colonização.

A partir dos discursos existentes, dentro destas imagens é perceptivel a invenção do nativo, caracterizada pelo isolamento do sujeito filmado, visível através da maneira como é filmado, o modo dos corpos e os rostos serem captados, com discursos que diferenciam a raça portuguesa das raças africanas, usando uma linguagem de inferiorização que constrói o discurso colonial.

Nestas imagens em movimento o uso do instrumento cinematográfico parece ter como objectivo o de identificar e catalogar os sujeitos para marcar a diversidade (os enquadramentos, os planos, a ordem didascálica, o uso das palavras construído no abuso de indígena, preto, 
batuques, primitivo a animalização do corpo do nativo, e apresentação recorrente de aspectos ligados à limpeza, às danças, à oração) através de uma linguagem que se fundamenta no racismo científico, tudo para justificar a missão civilizadora.

Sem dúvida, o dispositivo cinematográfico ajuda a criar um saber com base na experiência colonial, que poderiamos designar por encenação fílmica da ideia colonizadora e da política de "salvar almas mas educando corpos para o trabalho" de António Enes (Alexandre, 1999, p. 136).

Se considerarmos, como sugere a crítica e a história cinematográfica portuguesa, que o cinema nacional se caracteriza pela ausência de géneros temáticos e pelo domínio de assuntos relativos à identidade nacional, não seria pretencioso avançar com a ideia de que o cinema de carácter colonial reflecte nas imagens a identidade imperial portuguesa, enraizado numa oscilação entre o sentimento de inadequação frente aos outros colonialismos e a exaltação constante duma projeção imaginada de ser potência colonial. Angola, Moçambique, Guiné-Bissau, Cabo Verde, S. Tomé e Príncipe e os seus habitantes serão imortalizados na máquina cinematográfica do Estado, segundo as características da acção colonial portuguesa, mão-de-obra para o trabalho, exploração dos recursos naturais e humanos, e através das características dos aspectos culturais destes povos, onde o paradigma identitário considera a alteridade como uma categoria absoluta, fechando-a num mero produto segundo lógicas de exclusão.

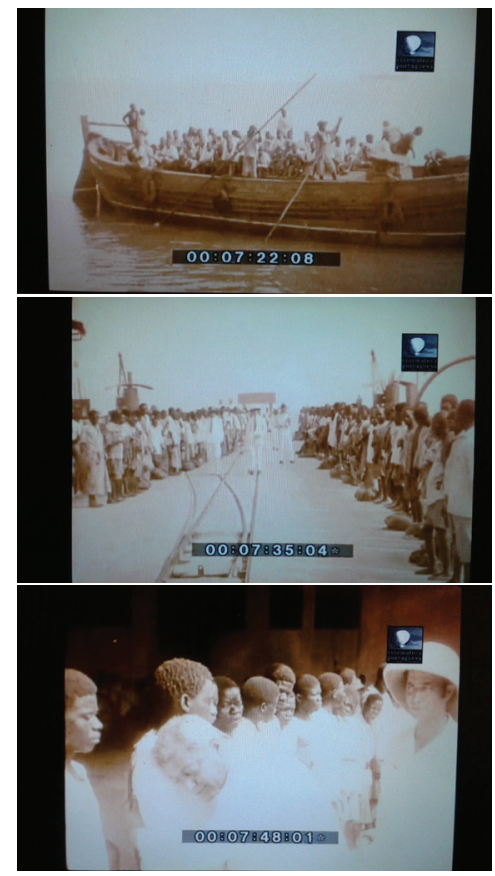

Fig.1,2,3 @Cinemateca Portuguesa, São Tomé Agrícola e Industrial, A. Seara, AGC- Serviços Cinematograficos do Exército, 1929. 

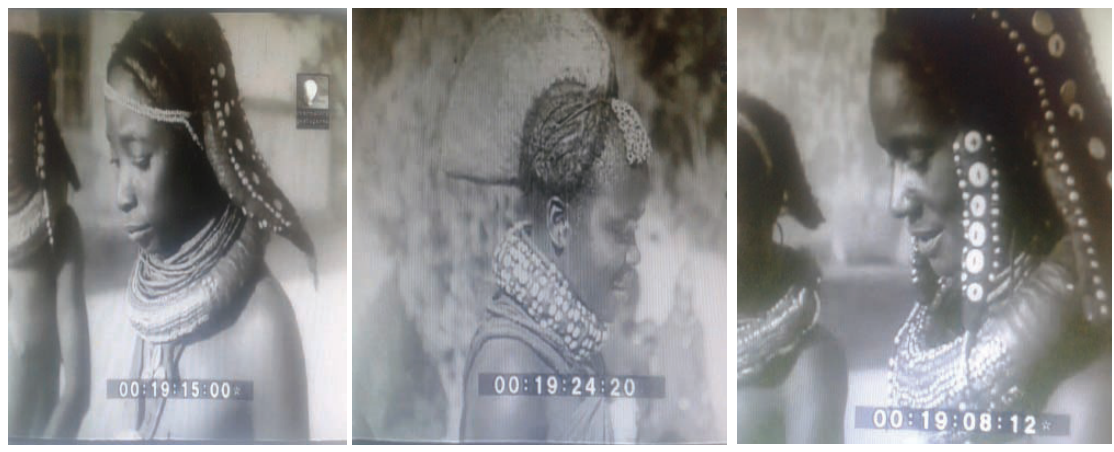

Fig. 4, 5, 6 @Cinemateca Portuguesa, Acção Colonizadora dos Portugueses, Antonio Antunes da Mata, AGU, 1932.
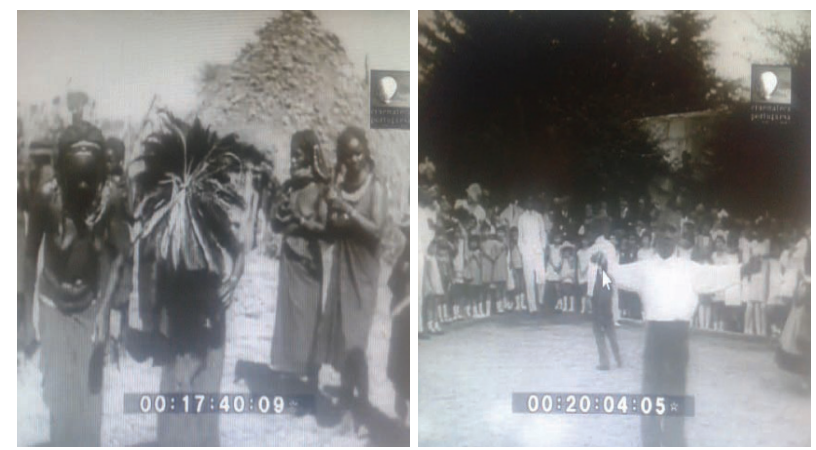

[Fig. 7, 8] @ Cinemateca Portuguesa, Acção Colonizadora dos Portugueses, Antonio Antunes da Mata, AGU, 1932.

Inspeções, raça ao trabalho, a desobjetivização dos corpos dos homens e das mulheres negros, a retórica das danças, da nudez do corpo feminino, a imponência das cartografias coloniais são só alguns dos tópicos que a filmografia documental nos oferece.

O Estado, na sua expressão cinematográfica, como é o exemplo do papel desempenhado pelos Serviços Cinematográficos do Exército, é fundamental para entender o discurso construído sobre o poder do controlo e da visualidade dos corpos diferentes e diferenciados.

O que se desenvolve dentro das produções fílmicas, entre ordenamento e visualidade, é o pensamento já pensado, isto é, o estereótipo 
como processo de ordenação, um atalho, uma referência ao 'mundo' e uma expressão por parte de quem o controla e lhe dá definição segundo os interesses que mais lhe forem próprios (Dyer, 2004, p. 25); é nesse sentido que os estereótipos organizam os dados que recebemos do mundo com critérios específicos.

Homi Bhabha no ensaio The other question, the stereotipe and colonial discourse (Bhabha, 1983, p. 13) define o estereótipo como ponto principal da subjectividade no discurso colonial, não se trata duma simplificação enquanto falsa representação duma realidade, é uma simplificação enquanto forma fixa de representação que, rejeitando o jogo das diversidades, constitui um problema em termos de representação do sujeito nos seus significados de relações psíquicas e sociais. Para além da visualidade e inflexibilidade da representação, poderiamos usar a expressão visageité, isto é, a relação entre o rosto e o poder, do papel e da função do rostro dentro dos aparatos do poder (Bhabha, 1983, p. 13).

Uma relação, segundo Deleuze, pode ser rentável à medida em que se concretiza a "produção de rostos", e os documentários em questão produzem inúmeros rostos.

Nesta relação entre supremacia do narrador e inferioridade do Outro de que se narra, a ambiguidade e a malícia com que se cria o corpo do sujeito feminino, entre nudez e penteados e a animalização do corpo masculino, onde o tema dominante é a mão-de-obra, irão fundamentar o discurso colonial como história de uma relação violenta, em que a palavra do poder colonial vê a sua enunciação na reprodução do silêncio do Outro.

No ensaio Cultural Identities and Diaspora (Hall, 1990), Stuart Hall que aponta reflexões sobre identidade, cultura e diaspora à volta do cinema caraíba, lembra-nos como as práticas de representação implicam sempre uma posição de enunciação, como o que dizemos é sempre contextualizado e tem posicionamento. 
Hall apresenta-nos duas possibilidades de pensar na identidade cultural: a primeira posição fala de identidade cultural em termos duma cultura partilhada, uma unicidade que como diz Frantz Fanon é uma pesquisa apaixonada na descoberta duma época de esplendor e lindíssima que, apesar da miséria actual, do desprezo por si, da renúncia e da renegação, reabilita-nos, ao mesmo tempo, frente a nós próprios e frente aos outros.

A segunda visão da identidade cultural, interligada com a primeira, reconhece os pontos críticos de profunda e significativa diferença, isto é, as fracturas e a descontinuidade nesta unicidade.

As identidades - sublinha Stuart Hall - vivem numa contínua trasformação e são sujeitas à acção contínua da história, da cultura e do poder; as identidades são os nomes das diferentes maneiras em que somos posicionados das narrações do passado e em que nós próprios nos posicionamos.

Só a partir desta segunda posição, segundo Hall, é que podemos compreender de maneira completa a condição traumática da experiência colonial.

No mesmo ensaio, Hall, continua na apresentação da construção da alteridade, falando da presença europeia dentro do contexto do Caribe, e que na realidade aplica-se bem aos vários contextos de colonização.

Nas palavras do autor jamaicano, esta presença nas representaçõoes visuais, tem posicionado o sujeito negro dentro dos regimes de dominação da representação através do discurso colonial, das literaturas de aventura e descoberta, do fascínio pelo exótico, do olhar do esplorador e do etnógrafo e das linguagens transferidas no campo do turismo, entre outros.

Representações de inferiorização que, como escreve Bell Hooks na obra Race and representations (1992), é através do controlo das imagens dentro das relações entre escravidão e supremacia que se concretiza a continuação de um sistema de dominação racial. 
Concluindo, o arquivo digital da Cinemateca Portuguesa apresenta-se como mais um cofre a descobrir, um lugar onde, para além de olhar sobre o discurso colonial do cinema português dos anos trinta, é um caminho para lidar com este passado e com a herança visual que nos deixou. Estamos perante a possibilidade de traçar outros percursos dentro e fora destes dispositivos arquivais. E num olhar capaz de re-memorar, isto é, para além da recolha e gravação deste material, é importante reconhecer a existência, ainda hoje, de histórias e culturas excluídas das narrações dominantes: dar voz e ouvir estas palavras significa estudar e desconstruir a herança das relações entre dominação e representação. O objectivo é dissipar as identidades criadas no olhar colonizador de representação da alteridade e, em relação às imagens, não se trata de propor a fetichização do "arquivo colonial" como objecto do gesto de montagem, trata-se de interrogá-lo através desse gesto de abertura e montagem-outra.

É assim que nos espaços onde a representação é o processo de criação de estereótipos, de sujeitos silenciosos e indivisíveis que a imaginação através da recuperação nos revela e cria a possibilidade dum encontro com o/a Outro/a que fala e produz os seus sinais, e que nos imagina por sua vez.

Repensar os arquivos, num discurso pós-colonial, representa uma tarefa crucial para sair das narrações de supremacia que até hoje foram feitas à volta da construção do Outro narrado.

Libertar os saberes da colonialidade, reconhecer a pluralidade das histórias.

Muitas seriam as reflexões a colocar para desconstruir aqueles dispositivos internos às instituições de conservação dos materiais que reflectem o passado colonial, em que são evidentes as relações de poder que a herança colonial revela. Torna-se ainda mais urgente a necessidade de reencontrar percursos-outros frente às lógicas de conservação canónicas, trata-se de aprender a re-memorar, não só recolher e registar que existiram histórias e culturas, artes até hoje 
excluídas mas também registar a centralidade da herança das relações entre dominação e representação actualmente ainda existentes, para que contaminação e pluralidade de vozes sejam as características de um pensamento cultural descolonizado na época pós-colonial.

\section{Bibliografia}

Alexandre, Valentim (1999), "Configurações políticas"; "Ruptura e estruturação de um novo império”, BETHENCOURT, Francisco; CHAUDHURI, Kirti (dir.), História da Expansão Portuguesa, vol. 4, 1999: ed., Lisboa, Edições 70.

Baptista, Tiago (2012), "Das "vistas" ao documentário: a não-ficção muda em Portugal", Panorama 2012 (Lisboa: CML/Videote Apordoc, 2012), 37-42.

Bhabha, Homi, (1983), "The Other Question Reconsiders the Stereotype and colonial Discourse”. Screen 24.6, 1994 Trad. Manuela Ribeiro Sanches.

Deianira, Amico, (2014) Entrevista a Marco Scotini: l'archivio come dispositivo tra estetica e pedagogia, http://news.mytemplart.com/it/intervista-marco-scotinilarchivio-come-dispositivo-tra-estetica-e-pedagogia/.

Deleuze, Gilles, (1987), A Thousand plateaus Capitalism and Schizophrenia Gilles Deleuze Felix Guattari, Translation and Foreword by Brian Massumi, University of Minnesota Press Minneapolis London.

Derrida, Jacques, (1990), (prefazione a) Du droit à la philosophie, Ed. Galilée, Paris.

Dyer, Richard., (2004), Dell'immagine, Saggi sulla rappresentazione, Torino, Kaplan.

Grechi, Giulia, (2014), Burning archives, La memoria del corpo tra archivi etnografici, colonialismo e arte contemporanea, $<<$ Roots \& Rootes $>>$, Periodico Trimestrale, Anno IV, n.3. agosto-ottobre.

Hall, Stuart, (1990), Cultural Identity and Diaspora. Hall, in Rutherfors, J. (ed.). Identity Community, Culture, Difference, Lawrence E Wishart, London, United Kingdom.

Mbembe, Achille (2002) The Power of the Archive and Its Limits. In Refiguring the Archive (ed.) C. Hamilton et al., 19-26. Boston: Kluwer Academic Publishers.

Mirzoeff, Nicholas, (1998), Race and identity in colonial and postcolonial culture, Introduction to part four, in Mirzoeff, Nicholas, The visual culture reader, London and New York Routledge.

Piçarra, Ramos, Maria do Carmo (2012) Azuis ultramarinos: propaganda colonial nas actualidades filmadas do Estado Novo e censura a tres filmes de autor, Tese de Doutoramento em Ciências da Comunicação, Departamento de Ciências Sociais e Comunicação, FCSH.

Piçarra Ramos, Maria do Carmo, (2013), Angola, o Nascimento de uma Nação (Volume I): o cinema do Império, Guerra \&Paz Ed., Lisboa.

Pimentel, Joana, (2007), “Abrir os Cofres”, in Textos CP, (2007) Pasta 102. 367-368, Genérico e notas sobre o filme, PP CP, 14 de Junho de 2007. 